\title{
EVALUATION OF ECOLOGICAL ENVIRONMENT SECURITY IN CONTIGUOUS POVERTY ALLEVIATION AREA OF SICHUAN PROVINCE
}

\author{
Xianwei $^{1 *}$,Chenyibo ${ }^{1}$, Chenjie ${ }^{1}$, Luoxiang ${ }^{1}$, Shaohuaiyong ${ }^{2}$ \\ ${ }^{1}$ Chengdu University of Information Technology,China-xianwei@ cuit.edu.cn \\ ${ }^{2}$ Chengdu University of Technology,China-Shaohuaiyong@cdut.cn
}

KEY WORDS: Ecological Environment Safety;Contiguous Poverty Alleviation Area; Ecological Environment Safety Assessment; Analytic Hierarchy Process

\begin{abstract}
:
According to the overall requirements of ecological construction and environmental protection, rely on the national key ecological engineering, strengthen ecological environmental restoration and protection, improve forest cover, control soil erosion, construct important ecological security barrier in poor areas, inhibit poverty alleviation through ecological security in this area from environmental damage to the vicious cycle of poverty. Obviously, the dynamic monitoring of ecological security in contiguous destitute areas of Sichuan province has a policy sense of urgency and practical significance. This paper adopts RS technology and GIS technology to select the Luhe region of Jinchuan county and Ganzi prefecture as the research area, combined with the characteristics of ecological environment in poor areas, the impact factors of ecological environment are determined as land use type, terrain slope, vegetation cover, surface water, soil moisture and other factors. Using the ecological environmental safety assessment model, the ecological environment safety index is calculated. According to the index, the ecological environment safety of the research area is divided into four levels. The ecological environment safety classification map of 1990 in 2009 is obtained. It can be seen that with the human modern life and improve their economic level, the surrounding environment will be destroyed, because the research area ecological environment is now in good, the ecological environment generally tends to be stable. We should keep its ecological security good and improve local economic income. The relationship between ecological environmental security and economic coordinated development in poor areas has very important strategic significance.
\end{abstract}

\section{INTRODUCTION}

The contiguous poverty-stricken areas are the core of China's current poverty alleviation and development work. The previous poverty alleviation work only focused on the economic development basically, and little considerate the impact of ecological and environmental security. However, in most of China's poor areas, the ecological environment is fragile. How to promote the coordinated development of the economy and ecological environment has always been the focus of attention. Therefore, strengthening the evaluation of the ecoenvironmental safety in contiguous regions is of important practical significance for formulating a sustainable development strategy for regional poverty alleviation.

The Aba Tibetan and Qiang Autonomous Prefecture and Ganzi Tibetan Autonomous Prefecture in Sichuan Province are areas where the ecological security is very fragile in the western of China. This area is also one of the typical poverty-stricken and a key poverty alleviation area in the country. Formulating an ecological safety evaluation system for poverty alleviation and development in the new period of the region. Researching the temporal and spatial changes of the ecological environment in the area. Both are of practical significance to the rational development and sustainable development of resources in the area. Research can provide data foundation and policy basis for promoting the coordinated development of the economy and ecology in the study area.

\section{STUDY AREA OVERVIEW AND DATA BASE}

\subsection{Overview of the Study Area}

The study is related to eco-environmental safety assessment studies, and selected the Jinchuan County of the Aba Prefecture in Sichuan Province and Luhuo County of the Ganzi Prefecture, as research areas (Fig. 1).

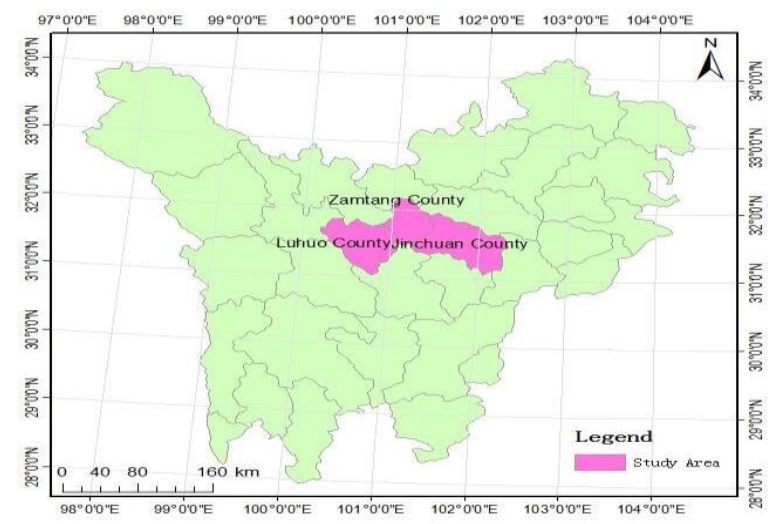

Figure 1. Overview of the study area

Both Jinchuan County and Luhuo County are typical hardship areas in China. Both counties are typical semi-agricultural and pastoral counties. With dense forests, the two counties are key original forest areas in the southwest and one of the important water conservation areas in the upper reaches of the Yangtze River. The main economic pillars of the past in the study area wood harvesting has been greatly reduced. Combined with the policy of returning farmland to forests, the area of cultivated 
land has been reduced, people's lives have been greatly affected and the county's economic level has been at a backward stage. As of 2012, the rural population of Jinchuan County was nearly $67 \%$, and the per capita net income of farmers and herdsmen was 3,896 yuan, which was lower than the national average of $3,949.58$ yuan, and the natural population growth rate was 2.55 times that of the whole country. Luohu County has a rural population of nearly $70 \%$. The per capita net income of farmers and herdsmen is 3596 Yuan, which is lower than the national average of 3949.58 yuan. The natural population growth rate is 3.01 times that of the country. Therefore, the region faces economic lag, excessive population growth, low level of technology, Poor medical and health conditions, backward infrastructure and other issues

\subsection{Data Foundation}

The data were selected from the Landsat TM remote sensing image data in the summer of 1990,1995,2000,2005 and 2009.TM3 and TM4 bands are used to extract NDVI; TM2 and TM4 band combinations are used to extract surface water bodies; TM4 and TM5 band combinations are used to extract urban residents. The elevation data uses global digital elevation model (GDEM) data with a resolution of $30 \mathrm{~m}$ to extract topographic data from the study area.

\section{ECOLOGICAL ENVIRONMENTAL SAFETY EVALUATION}

3.1 Determination and Handling of Eco-environmental Safety Evaluation Indicators

\begin{tabular}{|c|c|c|}
\hline Evaluation index & classification & $\begin{array}{c}\text { Normalized } \\
\text { value }\end{array}$ \\
\hline & Water & 7 \\
Land use type & Meodland & 5 \\
& Residents & 3 \\
& Barely & 1 \\
& $\leq 10^{\circ}$ & 1 \\
Topography/Slope & $10^{\circ}-20^{\circ}$ & 3 \\
& $20^{\circ}-40^{\circ}$ & 5 \\
Vegetation & $\geq 40^{\circ}$ & 7 \\
coverage/NDVI & -1 & 7 \\
& $0-0.3$ & 5 \\
Soil & $0.3-0.5$ & 3 \\
moisture/NDWI & $0.5-1$ & 1 \\
& $\leq 10$ & 1 \\
The surface waters & $10-20$ & 3 \\
& $20-40$ & 5 \\
& Anhydrous & 7 \\
\hline
\end{tabular}

Table 1 Classification of evaluation indicators and standardization

Based on the principles of scientificity, feasibility, and representativeness, five indicators of land use type, topography/land slope, vegetation coverage, surface water body, and soil moisture were selected as assessment factors for ecological environment safety in the study area. When assessing, in order to prevent a large error, each influence factor needs to be quantified and graded under the same standard. Standardize the evaluation indicators, the results of the classification and standardization of various indicators are shown in Table 1.

\subsection{Determination of the Weight of Evaluation Factors}

AHP chromatography was used to determine the weight of each evaluation factor. The weights of land use, terrain gradient, vegetation cover, surface water body, and soil moisture in the criterion layer are obtained by constructing a judgment matrix. The judgment matrix of the evaluation factors of the ecological environment in the study area is shown in Table 2.According to the judgment matrix, the weights of the impact factors of ecoenvironmental safety are as shown in Table 3 .

\begin{tabular}{|c|c|c|c|c|c|}
\hline $\begin{array}{l}\text { Evaluation } \\
\text { elements }\end{array}$ & terrain & $\begin{array}{l}\text { Vegetation } \\
\text { coverage }\end{array}$ & $\begin{array}{l}\text { Land } \\
\text { use }\end{array}$ & $\begin{array}{l}\text { The } \\
\text { surface } \\
\text { waters }\end{array}$ & $\begin{array}{l}\text { Soil } \\
\text { moisture }\end{array}$ \\
\hline terrain & $1: 1$ & $3: 1$ & $3: 1$ & $5: 1$ & $7: 1$ \\
\hline $\begin{array}{l}\text { Vegetation } \\
\text { coverage }\end{array}$ & $1: 3$ & $1: 1$ & $1: 1$ & $3: 1$ & $5: 1$ \\
\hline Land use & $1: 3$ & $1: 1$ & $1: 1$ & $3: 1$ & $5: 1$ \\
\hline $\begin{array}{c}\text { The surface } \\
\text { waters }\end{array}$ & $1: 5$ & $1: 3$ & $1: 3$ & $1: 1$ & $3: 1$ \\
\hline $\begin{array}{c}\text { Soil } \\
\text { moisture }\end{array}$ & $1: 7$ & $1: 5$ & $1: 5$ & $1: 3$ & $1: 1$ \\
\hline
\end{tabular}

Table 2 Comparison scale of each evaluation element

\begin{tabular}{|c|l|c|c|c|c|}
\hline $\begin{array}{l}\text { Evaluation } \\
\text { elements }\end{array}$ & $\begin{array}{l}\text { Land } \\
\text { use }\end{array}$ & $\begin{array}{l}\text { Terrain } \\
\text { / slope }\end{array}$ & $\begin{array}{l}\text { Vegetation } \\
\text { coverage }\end{array}$ & $\begin{array}{l}\text { The } \\
\text { surface } \\
\text { waters }\end{array}$ & $\begin{array}{l}\text { Soil } \\
\text { moisture }\end{array}$ \\
\hline Weight & 0.466 & 0.203 & 0.203 & 0.086 & 0.042 \\
\hline \multicolumn{5}{|c|}{ Table 3 Weights of evaluation elements }
\end{tabular}

\subsection{Ecological Environmental Safety Evaluation}

The $\mathrm{km}$ grid was selected as the assessment unit for the ecological environment in the study area. The AHP method was used to conduct a comprehensive evaluation method of ecological environmental safety impacts.

Based on the standardization of five factors affecting land use (C1), topography/gradient (C2), vegetation coverage (C3), surface water body (C4), and soil moisture (C5) in the ecoenvironmental security of typical poverty-stricken areas and contiguous poverty-stricken areas(Examples of contiguous films in Jinchuan County and Luhuo County) result, the weight values calculated in Table 3, formula 1 is used to calculate the eco-environmental safety factor for each evaluation unit in the study area.

$$
W=0.466 \times C 1+0.203 \times C 2+0.203 \times C 3+0.086 \times C 4+0.042 \times C 5
$$

The comprehensive evaluation index value range is $1-7$.The different indicators of the ecological environment safety index represent the degree of the ecological environment safety status. In order to facilitate comparison and analysis, the environmental assessment index was graded, and the overall ecological environmental assessment results were divided into excellent (6-7), good (4-6), medium (2-4), and poor (1-2) Level 4, see Table 4.

The grading spatial distribution characteristics of the composite index of different levels reflect the regional differences in the ecological environment security status. The results of the classification of eco-environmental security assessments in the study area from 1990 to 2009 are shown in Figure 2. 


\begin{tabular}{|c|c|l|}
\hline Rating & $\begin{array}{l}\text { Evaluation } \\
\text { Index }\end{array}$ & \multicolumn{1}{c|}{ Instructions } \\
\hline Excellent & $6-7$ & $\begin{array}{l}\text { The ecological environment is } \\
\text { basically undamaged, and the } \\
\text { ecological system has a complete } \\
\text { structure and strong functions; } \\
\text { The ecological environment is } \\
\text { slightly damaged, the ecological } \\
\text { system is complete and its } \\
\text { functions are strong } \\
\text { The ecological environment is } \\
\text { subject to a small amount of } \\
\text { damage, and the ecosystem can } \\
\text { maintain its basic functions and } \\
\text { can be restored under general } \\
\text { disturbances. } \\
\text { The ecological environment has } \\
\text { been damaged, the structure of the } \\
\text { ecosystem has changed greatly, } \\
\text { the functions are incomplete, the } \\
\text { problems of the ecological } \\
\text { environment are large, and there } \\
\text { are many disasters; }\end{array}$ \\
\hline
\end{tabular}

Table 4. Classification Table of Ecological Environment Safety
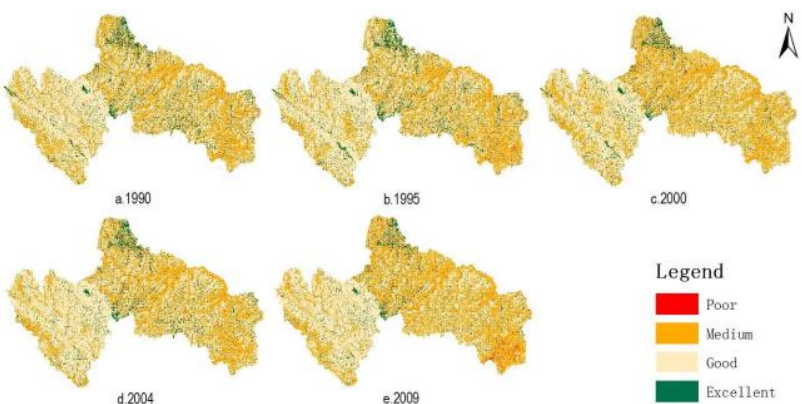

c.2000

$\stackrel{0}{25} \quad 50,100 \mathrm{~km}$

Figure 2 Evaluation map of eco-environmental safety in the study area from 1990 to 2009

\section{ANALYSIS OF ECOLOGICAL ENVIRONMENTAL SAFETY EVALUATION RESUITS IN THE STUDY} AREA

\begin{tabular}{|c|l|l|l|l|l|}
\hline years & 1990 & 1995 & 2000 & 2004 & 2009 \\
\hline $\begin{array}{c}\text { Poor } \\
(\%)\end{array}$ & $0.02 \%$ & $0.07 \%$ & $0.06 \%$ & $0.04 \%$ & $0.21 \%$ \\
$\begin{array}{c}\text { medium } \\
(\%) \\
\text { good } \\
(\%)\end{array}$ & $18.70 \%$ & $19.52 \%$ & $20.73 \%$ & $18.21 \%$ & $21.23 \%$ \\
$\begin{array}{c}\text { excellet } \\
(\%)\end{array}$ & $3.10 \%$ & $2.30 \%$ & $2.23 \%$ & $2.65 \%$ & $2.02 \%$ \\
\hline
\end{tabular}

Table 5 Percentage of evaluation area of eco-environmental security in the study area from 1990 to 2009

The area of the ecological environment security classification results in the statistical research area was calculated, and the area percentage of the ecological environment safety in the study area from 1990 to 2009 was shown in Table 5 and Figure 3.
As can be seen from Figure 2, from the spatial distribution point of view, the area of ecological environment safety assessment is "excellent" and "poor". The areas of "medium" and "good" are larger and closer. The area of the two accounts for about $97 \%$ of the total area. It shows that the eco-environmental security in the study area is generally at a medium level. The areas with medium or poor evaluation results are mainly distributed in the southwest of Jinchuan County and west of Luhuo County. The areas with good evaluation results are mainly distributed in the middle of Jinchuan County and the central and eastern parts of Luhuo County. The areas with excellent evaluation results are mainly distributed in northwest of Jinchuan County. From Table 6 and Figure 3, it can be seen that in 1990, the difference between the area percentage of "good" and "poor" ecoenvironmental safety assessment was the largest. The percentage of the area where the assessment of ecological environment safety is "poor" has been kept below $0.05 \%$,and is mostly around $0.05 \%$; the area percentage of ecological environment safety assessment as "middle" has remained stable at around $20 \%$, fluctuating around $36 \%$; The percentage of the area where the environmental safety assessment was "good" remained at about $78 \%$, and it was only $78 \%$ higher in 1990 and 2004 ; the percentage of the area where the eco-environmental safety was evaluated as "excellent" fluctuates around $2.5 \%$. As a result, the area percentage of safety assessments of "excellent", "good", "medium", and "poor" changed little over time and remained stable for a long period of time.

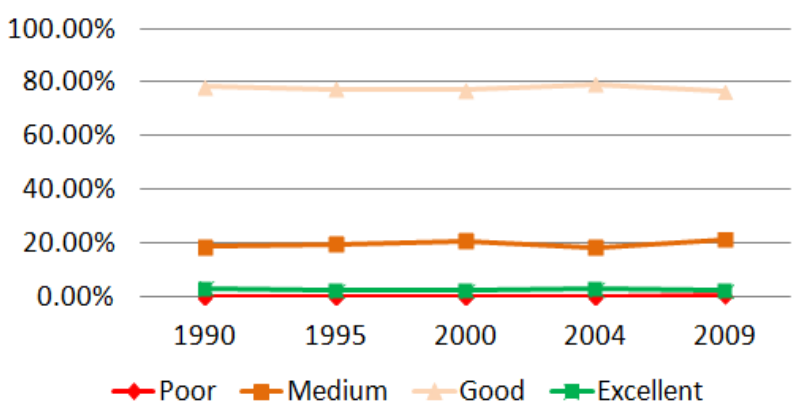

Figure 3. Grading chart of eco-environmental safety classification for contiguous destitute areas (in Jinchuan County and Luhuo County) from 1990 to 2009

From the perspective of changes in time, the areas with the largest and smallest percentages of the ecological safety assessment as "poor" were 2009 and 1990 respectively; the areas with the largest and smallest percentages of "middle" were 1990 and 1995 respectively; The largest and smallest years for "good" are 2004 and 2009 respectively; the areas with the highest and lowest percentages of "excellent" were 1990 and 2009 respectively. In summary, the area percentage of ecological environment safety assessment as "excellent" in 1990 was the largest in all years, as high as $3.10 \%$; and the area percentage of "good" was $78.18 \%$; the assessment of ecological environment safety was "medium" and the area percentage of poor" is the smallest among the research years, which is $18.70 \%$ and $0.02 \%$ respectively. On the contrary, in 2009 , the percentage of the area where ecological environment safety was evaluated as "excellent" and "good" was the smallest among all years, with $2.02 \%$ and $76.54 \%$ respectively; The percentage of area where the ecological environment was evaluated as "medium" and "poor" was the largest among the research years, which was $21.23 \%$ and $0.21 \%$ respectively.

From this, it can be seen that the ecological environment in the study area is classified as "excellent" and "good" as a whole 
tends to deteriorate, while the assessment is that "medium" tends to rise, and the area evaluated as "poor" increases at an accelerating pace. According to the corresponding data, the income of local residents continued to increase from 1990 to 2009 , indicating that the local ecological environment security and poverty levels show the same direction. Therefore, local residents should pay attention to the use of resources in the development of resources and the environment.

In summary, the best and worst years of the ecology were 1990 and 2009 respectively. And from 1990 to 2009 ,the percentage of the area where the assessment of ecological environment safety as "poor" is generally rising, while the area percentage of the corresponding ecological environment safety assessment as "excellent" has generally declined, but there was a clear increase in 2004. Therefore, the eco-environmental security classification of contiguous destitute areas (in Jinchuan County and Luhuo County as an example) is generally in the state of "excellent" and "good" tends to be worse, and the assessment is that "middle" tends to rise. The state that is evaluated as "poor" tends to change badly.

\section{CONCLUSIONS AND PROSPECTS}

In this study, AHP was used to evaluate the ecological environment safety in contiguous destitute areas (Jinchuan County and Luhuo County as an example).The results show that the ecological environment in the study area is generally at a medium level from the perspective of spatial distribution. The results of eco-environmental safety assessment have a larger area of "medium" and "good", accounting for $97 \%$ of the total area. It is also close. Judging from the development of time, the classification of the ecological environment in the research area is generally "excellent" and "good" tends to be in a worsening state, while the assessment is that "middle" tends to rise, and the area evaluated as "poor" has accelerated growth rate. In terms of the income level of the local population, which has continued to increase from 1990 to 2009, and the ecological environment security and poverty levels showed greater consistency.

Therefore, when using resources, local residents should pay atte ntion to lessons learned from environmental degradation during economic development in other regions, strengthen the restorati on and protection of the ecological environment, increase forest coverage, control soil erosion, and build important ecological se curity barriers in poverty-stricken areas. From the aspect of ecol ogical security, we must curb the vicious circle of poverty allevi ation and development in destitute areas from environmental de struction to poverty intensification.

\section{ACKNOWLEDGEMENTS}

This study is supported and funded by the Research Fund for the Science and Technology Department of Sichuan Province (Grant No. 2017SZ0088). The authors greatly appreciate the support of the Scientific Innovation Team of Remote Sensing Science and Technology of Chengdu University of Information Technology.

\section{REFERENCES}

Wang, S.L., Jiu, M.C., 2013. Research Hotspot and Revelation of Tibetan Areas Studies in the Four Provinces of Qinghai, Sich uan, Yunnan and Gansu. Journal of Changsha Un iversity of Sc ience \& Technology.
Mao, W.Y., 1998. Introduction to Ecological Environmental Im pact Assessment. Beijing:China Environmental Science Press, $\mathrm{p}$ p. 1-20.

Yang, J.W., 2004. Sichuan Poverty Situation and Problem in Ti betan Areas. Tibet Studies.

Legg, C.A., 1990. Applications of remote sensing to environme ntal aspects of surface mining operations in the United Kingdo $\mathrm{m}$, Remote sensing: an operational technology for the mining an d petroleum industries. Conference, IMM, London, pp. 159-164.

Venkataraman G., Kumar S.P., Ratha D.S., Inamdar A.B., Naga rajan $\mathrm{R}, 1997$. Open cast mine monitoring and environmental i mpact studies through remote sensing-a case study from Goa, In dia, Geocarto-International, vol.12,no.2, pp. 39-53.

Christian Fischer, Wolfgang Busch., 2002. Monitoring of Envir onmental changes caused by hard coal mining. Remote Sensing for Environmental Monitoring, GIS Applications, and Geology, Proceeding of SPIE, vol.4545.

Sun, H.L., 2000. ChinaResourceScienceEncyclopedia. China E ncyclopedia Publishing House,Petroleum University Press, Beij ing.

China Environmental Monitoring Station., 2004. China Environ mental Quality Evaluation Study.Beijing:China Environment Pr ess, pp. 1-5.

Du, M.Y, J., 2013. An Analysis of the Anti-poverty Approaches in Ethnic Areas from the Perspective of Social Capital: A Case Study of Sichuan Tibetan Area.Journal of Sichuan Administrati on College.

Tang, Z., 2005. Study on the Quality Assessment and Planning of Ecological Environment about County (Town)Area-In the Ca se of Zhuanghe.Master Thesis.

Bi , X.L,Hong, W., 2001. Advances of composite evaluation in ecological environment.System Sciemces \& Comprehensive Stu dies in Agriculture, 17(2), pp. 122-126.

Zheng, X.Q., Wang ,A.P., 2000. Study on the integrated assess ment of regional ecological environmental quality based on RS \& GIS for Shandong Province.Actaentiae Circumstantiae,20(4), pp. 489-493.

Ye, Y.P.,Liu, L.J., 2000. A Preliminary Study on Assessment In dicator System of Provincial Eco-EnvironmentalQualityinChina. ResearchofEnvironmentalences, 13(3), pp. 33-36.

Xia, F.R., 2011. Ecological environment assessment of Changsh an salt mine in the city of Zigong based on GIS and RS.Chengd u: Chengdu University of Technology [Master's Thesis].

Ma, L.L.,Tian,S.F.,Wang.N., 2013. Ecological environment eva lation of the mining area based on AHP and fuzzy mathematics. RemoteSensingforLandandResources, 25(3), pp. 165 -170.

Hu, B.R., 2009. Evaluation on the Ecological Environments bef ore and after 5.12 Wenchuan Earthquake by remote sensing and GIS.Chengdu: Chengdu University of Technology [Master's Th esis]. 
The International Archives of the Photogrammetry, Remote Sensing and Spatial Information Sciences, Volume XLII-3, 2018 ISPRS TC III Mid-term Symposium "Developments, Technologies and Applications in Remote Sensing", 7-10 May, Beijing, China

Eco-environmental status evaluation technical specification (tria 1), 2006. China Environment Press. 